\title{
Clinical Impact of Blood Testosterone Concentration on Cardio-Ankle Vascular Index in Female Patients With Type 2 Diabetes Mellitus
}

\author{
Takashi Hitsumoto
}

\begin{abstract}
Background: Information regarding testosterone as a significant risk factor of cardiovascular disease (CVD) in female patients with type 2 diabetes mellitus (DM) is limited. However, some clinical studies reported the importance of cardio-ankle vascular index (CAVI) as a novel physiological marker of arterial function in type $2 \mathrm{DM}$. This cross-sectional study aimed to elucidate the clinical effects of blood testosterone concentration on CAVI in female patients with type 2 DM.
\end{abstract}

Methods: A total of 238 postmenopausal patients including 97 with a history of CVD with type 2 DM (age (mean \pm standard deviation (SD)), $73 \pm 9$ years) were enrolled. CAVI was measured according to the standard technique, and serum total testosterone concentration (T-T) was also measured as a testosterone level marker in vivo. The relationship between CAVI and T-T was evaluated.

Results: CAVI is significantly higher (CVD vs. non-CVD: $10.2 \pm 1.2$ vs. $9.2 \pm 1.0, \mathrm{P}<0.001$ ), and log-T-T significantly lower (CVD vs. non-CVD: $1.2 \pm 0.2 \mathrm{ng} / \mathrm{dL}$ vs. $1.5 \pm 0.2 \mathrm{ng} / \mathrm{dL}, \mathrm{P}<0.001$ ) in patients with CVD than those without CVD. CAVI was significantly negatively correlated with $\log -\mathrm{T}-\mathrm{T}(\mathrm{r}=-0.41 ; \mathrm{P}<0.001)$. Furthermore, multiple regression analysis indicated that $\operatorname{CVD}(\beta=0.23 ; \mathrm{P}<0.001)$ and $\log$-T-T $(\beta=-0.18 ; \mathrm{P}<0.01)$ were selected as independent subordinate variables for CAVI.

Conclusions: This study showed that T-T was independently inversely associated with CAVI, indicating that low testosterone concentration is a considerable risk factor for the progression of arterial dysfunction in female patients with type $2 \mathrm{DM}$.

Keywords: Testosterone; Cardio-ankle vascular index; Cardiovascular disease; Skin autofluorescence; Oxidative stress; Female; Type 2 diabetes mellitus

Manuscript submitted December 22, 2018, accepted January 7, 2019

Hitsumoto Medical Clinic, 2-7-7, Takezakicyou, Shimonoseki City, Yamaguchi, 750-0025, Japan. Email: thitsu@jcom.home.ne.jp

doi: https://doi.org/10.14740/cr827

\section{Introduction}

Epidemiological and clinical studies reported the importance of type 2 diabetes mellitus (DM) as a risk factor of cardiovascular disease (CVD) in female patients [1-3]. In addition, some researchers reported that female patients with type 2 DM with a history of CVD had higher incidence of secondary CVD events than those without diabetes $[4,5]$. Therefore, CVD should be noted and prevented in female patients with type $2 \mathrm{DM}$.

Testosterone is an important sex hormone that influences various health problems in men. In particular, recent clinical studies reported that low blood testosterone concentration in men is closely associated with CVD incidence $[6,7]$. Furthermore, some researchers reported that low blood testosterone concentration is also an important CVD risk factor in male patients with type $2 \mathrm{DM}[8,9]$. On the contrary, female patients also produced testosterone, but at levels approximately $5-10 \%$ of those in men. The significance of blood testosterone concentration as a CVD risk factor in female patients remains controversial. Some clinical studies have demonstrated that high blood testosterone concentration in female patients is associated with CVD incidence $[10,11]$. However, another researcher reported that low blood testosterone concentration in female patients was associated with higher incidence of CVD events than those with high blood testosterone concentration [12]. Furthermore, information regarding the clinical significance of testosterone as a CVD risk factor in female patients with type $2 \mathrm{DM}$ is limited.

Cardio-ankle vascular index (CAVI) is a novel physiological marker of atherosclerosis, which reflects the arterial stiffness in the aortic, femoral, and tibial arteries [13]. This stiffness parameter has been reported to be independent of blood pressure levels during measurements. In addition, some clinical studies have indicated the importance of high CAVI as a CVD risk factor in patients with type 2 DM [14, $15]$.

To the best of the authors' knowledge, no study has assessed the relationship between testosterone concentration and CAVI in female patients with type $2 \mathrm{DM}$. Thus, this study aimed to elucidate the clinical significance of blood testosterone concentration as a risk factor for arterial dysfunction in female patients with type 2 DM using CAVI. 


\section{Materials and Methods}

\section{Patients}

This cross-sectional study was performed at the Hitsumoto Medical Clinic in Yamaguchi, Japan, between August 2016 and July 2018. The serum total testosterone concentration (TT), CAVI, and various clinical parameters were analyzed in 238 postmenopausal patients, including 97 with CVD history with type $2 \mathrm{DM}$ (age (mean \pm standard deviation (SD)), $73 \pm 9$ years). Patients administered dehydroepiandrosterone, estradiol, and testosterone were excluded. Clinical CVD history was defined as previous ischemic heart disease, cerebrovascular disease, peripheral arterial disease, or heart failure admission based on medical records. All patients provided informed consent, and the study protocol was approved by the local ethics committee of the Hitsumoto Medical Clinic (approval number: 2016-06).

\section{CAVI measurement}

CAVI was measured using the VaSera VS-1000 (Fukuda Denshi Co. Ltd., Tokyo, Japan) based on the previously described methods [13]. Briefly, the brachial and ankle pulse waves were determined using inflatable cuffs with the pressure maintained between 30 and $50 \mathrm{~mm} \mathrm{Hg}$ to ensure that the cuff pressure had a minimal effect on the systemic hemodynamics. Blood and pulse pressures were simultaneously obtained in lying supine position, after a $10-$ min rest in a quiet room. The CAVI in this study was the higher value obtained from the left and right extremities. CAVI was calculated using the Bramwell-Hill's equation: $\mathrm{CAVI}=\mathrm{a}\{(2 \rho / \Delta \mathrm{P}) \times \ln (\mathrm{Ps} / \mathrm{Pd}) \mathrm{PWV} 2\}+\mathrm{b}$, where $\mathrm{a}$ and $\mathrm{b}$ are constants, $\rho$ is blood density, $\Delta \mathrm{P}$ is Ps - Pd, Ps is systolic blood pressure, $\mathrm{Pd}$ is diastolic blood pressure, and PWV is pulse wave velocity.

\section{Evaluation of cardiovascular risk factors}

The degree of obesity was assessed using body mass index, calculated as the ratio of weight $(\mathrm{kg})$ to the square of height $\left(\mathrm{m}^{2}\right)$. A current smoker was defined as an individual who smoked at least one cigarette per day in the last 28 days. Right brachial blood pressure was measured twice using a mercury sphygmomanometer in sitting position. An average of two readings was used to determine systolic and diastolic blood pressures. Hypertension was defined as systolic blood pressure of $\geq 140 \mathrm{~mm} \mathrm{Hg}$, diastolic blood pressure of $\geq 90 \mathrm{~mm} \mathrm{Hg}$, or use of antihypertensive medication. Dyslipidemia was defined as a low-density lipoprotein cholesterol level of $\geq 140 \mathrm{mg} / \mathrm{dL}$, a high-density lipoprotein cholesterol level of $\leq 40 \mathrm{mg} / \mathrm{dL}$, a triglyceride level of $\geq 150 \mathrm{mg} / \mathrm{dL}$, or the use of antidyslipidemic medication. Skin autofluorescence (AF), reflecting the accumulation of advanced glycation end-products (AGEs) in tissues, was measured on the volar side of the forearm using a commercial instrument (AGE Reader; DiagnOptics, Gronin- gen, The Netherlands) as previously described [16].

Blood samples were collected from the antecubital vein in the morning after $12 \mathrm{~h}$ of fasting. The serum lipid, plasma glucose, serum estradiol, high-sensitivity C-reactive protein (hsCRP) as a marker of inflammation, and serum insulin concentrations, hemoglobin A1c levels, reactive oxygen metabolites (d-ROMs) test as a marker of oxidative stress, and T-T were subsequently measured. Total cholesterol and triglyceride concentrations were measured using the standard enzymatic methods. High-density lipoprotein cholesterol concentration was measured through selective inhibition. Low-density lipoprotein cholesterol concentration was calculated using the Friedewald formula [17]. Patients with a serum triglyceride concentration of $\geq 400 \mathrm{mg} / \mathrm{dL}$ were excluded because the method is accurate only below this concentration. Plasma glucose and serum insulin concentrations were measured using the glucose oxidase method and enzymatic immunoassay, respectively. To measure insulin resistance, the homeostatic model assessment of insulin resistance (HOMA-IR) was used as follows [18]: HOMA-IR = fasting glucose concentration $(\mathrm{mg} / \mathrm{dL}) \times$ fasting immunoreactive insulin concentration $(\mu \mathrm{g} / \mathrm{mL}) / 405$. The hemoglobin A1c levels were expressed using the National Glycohemoglobin Standardization Program. The hs-CRP concentration was measured using high-sensitivity, latex-enhanced immunonephelometric assay. The d-ROMs test, which reflects blood hydroperoxide concentrations, was performed using a commercial kit (Diacron, Grosseto, Italy) [19]. Serum estradiol concentration was measured using a commercial kit (ARCHITECT Estradiol II, Abbott Japan, Tokyo). The detection limit of estradiol using this kit is $5 \mathrm{pg} / \mathrm{mL}$. T-T was also measured using a commercial kit (ARCHITECT Testosterone II, Abbott Japan, Tokyo).

\section{Statistical analysis}

A commercially available statistical software program (StatView-J 5.0, Hulinks, Inc., Tokyo, Japan) was used for all statistical analyzes. Continuous variables were expressed as mean $\pm \mathrm{SD}$. Between-group comparisons were performed using the Student's $t$-test. The correlation coefficient was estimated using the Spearman's rank correlation analysis. Multivariate analysis was performed using multiple regression analysis. A P-value of $<0.05$ was considered statistically significant.

\section{Results}

The distribution of T-T and CAVI in the study population is shown in Figure 1, and baseline clinical characteristics are shown in Table 1. Distribution of actual T-T of the study population was not normally distributed, even though CAVI has nearly normal distribution. Therefore, log-T-T was calculated with similar normal distribution. The mean value of log-T-T was $1.4 \pm 0.3$ (range, $0.9-2.0$ ) ng/dL, and the mean value of CAVI was $9.6 \pm 1.2$ (range, 7.2 - 13.4). Comparisons of CAVI or log-T-T between patients without and with CVD are shown in Figure 2. CAVI is significantly higher and log-T-T significantly lower in patients with CVD than those without CVD. 

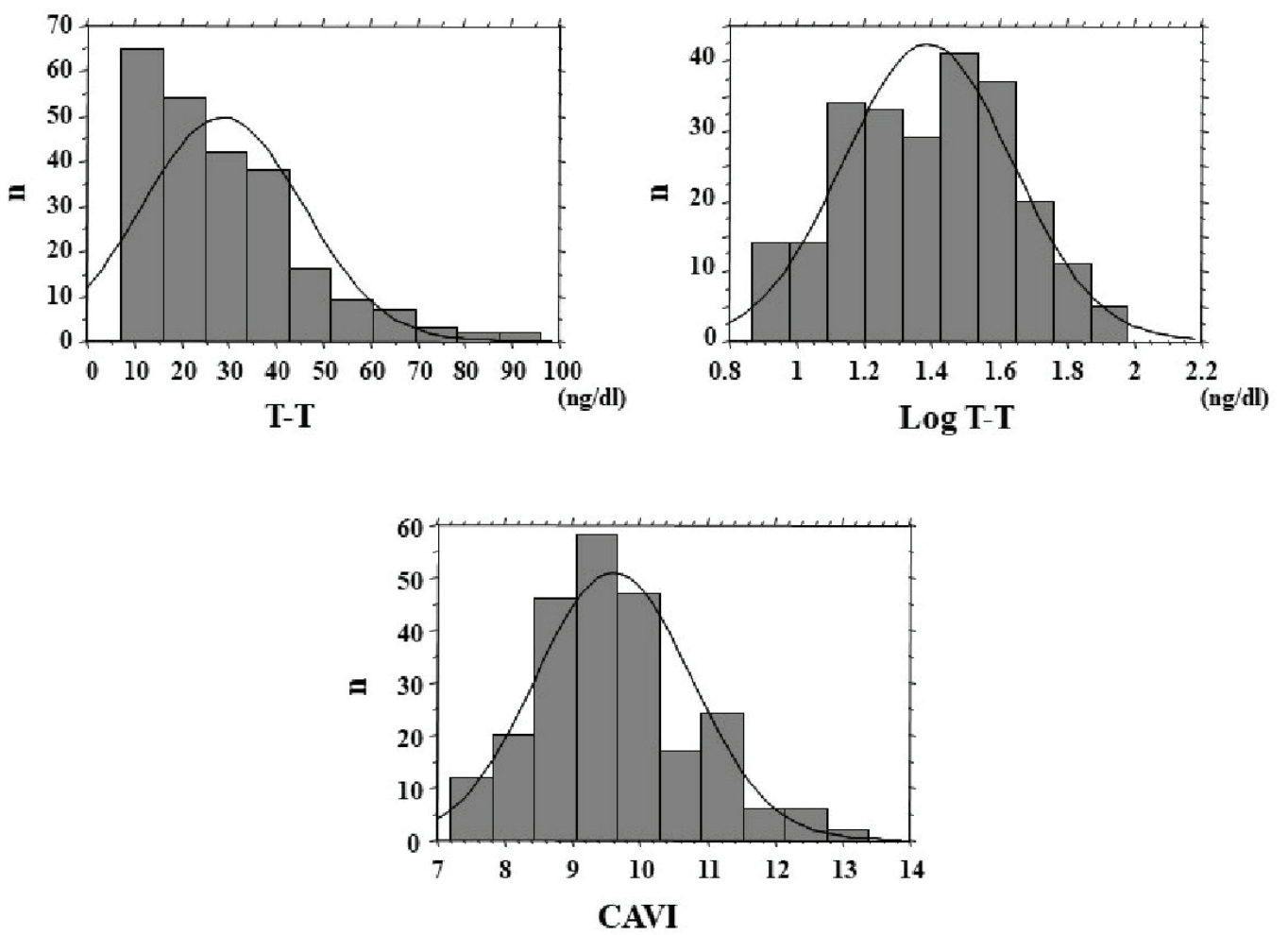

Figure 1. Distribution of T-T and CAVI. Distribution of actual T-T of the study population was not normally distributed, even though CAVI has nearly normal distribution. Therefore, log-T-T was calculated with similar normal distribution. T-T: total testosterone; CAVI: cardio-ankle vascular index.

The association between CAVI and T-T is shown in Figure 3. CAVI was significantly negatively correlated with log-T-T. Table 2 shows the association between CAVI or T-T and various clinical parameters. CAVI is significantly positively correlated with age, CVD history, hypertension, systolic blood pressure, hemoglobin A1c, skin AF, hs-CRP concentration, and dROMs. CAVI is also significantly negatively correlated with detection of serum estradiol concentration in serum estradiol detectable patients. Log-T-T is significantly negatively correlated with CVD history, hypertension, systolic blood pressure, HOMA-IR, hemoglobin A1c, skin AF, hs-CRP concentration, and d-ROMs. Log-T-T is also significantly positively correlated with detection of serum estradiol concentration in serum estradiol detectable patients. Table 3 shows the result of multiple regression analysis for CAVI or log-T-T as a subordinate factor. Explanatory factors were selected either by checking the multicollinearity among variables or by the stepwise method. Age, CVD history, log-T-T, skin AF, and d-ROMs test were selected as independent variables when CAVI was used as a subordinate factor. However, detection of estradiol, CAVI, CVD history, skin AF, and d-ROMs test were selected as independent variables when using log-T-T as a subordinate factor.

\section{Discussion}

In the present study, CAVI is significantly higher and log-T-T significantly lower in patients with CVD than those without CVD; furthermore, multiple regression analysis indicated that CVD was an independent variable for both CAVI and log-T-T as subordinate factors. Although this is a cross-sectional study, its results suggested that increased CAVI and decreased blood testosterone concentration were associated with CVD incidence in female patients with type 2 DM. In addition, CAVI was independently inversely associated with log-T-T, and skin $\mathrm{AF}$ as a marker of AGEs in tissues and d-ROMs test as a marker of oxidative stress were selected as independent variables for both CAVI and log-T-T as subordinate factors.

The CAVI principle is known as a marker of systemic arterial stiffness [13]. In addition, researchers reported that CAVI may reflect the endothelial function $[20,21]$. Thus, previous studies clarified that CAVI was a useful marker of arterial function. However, several mechanisms explaining the vascular protective effects of testosterone, such as smooth muscle cell function, endothelial function, and vascular calcification inhibition, have been reported [22-24]. Clinical studies also indicated that low blood testosterone concentration was significantly associated with impaired physiological markers for arterial function, such as PWV, flow-mediated dilatation, and augmentation index in men [25-27]. Furthermore, the results of this study indicated that low blood testosterone concentration was an important determining factor of arterial dysfunction in female patients with type 2 DM. Decreased estrogen level in female patients is widely known to be associated with various 
Table 1. Patient Characteristics

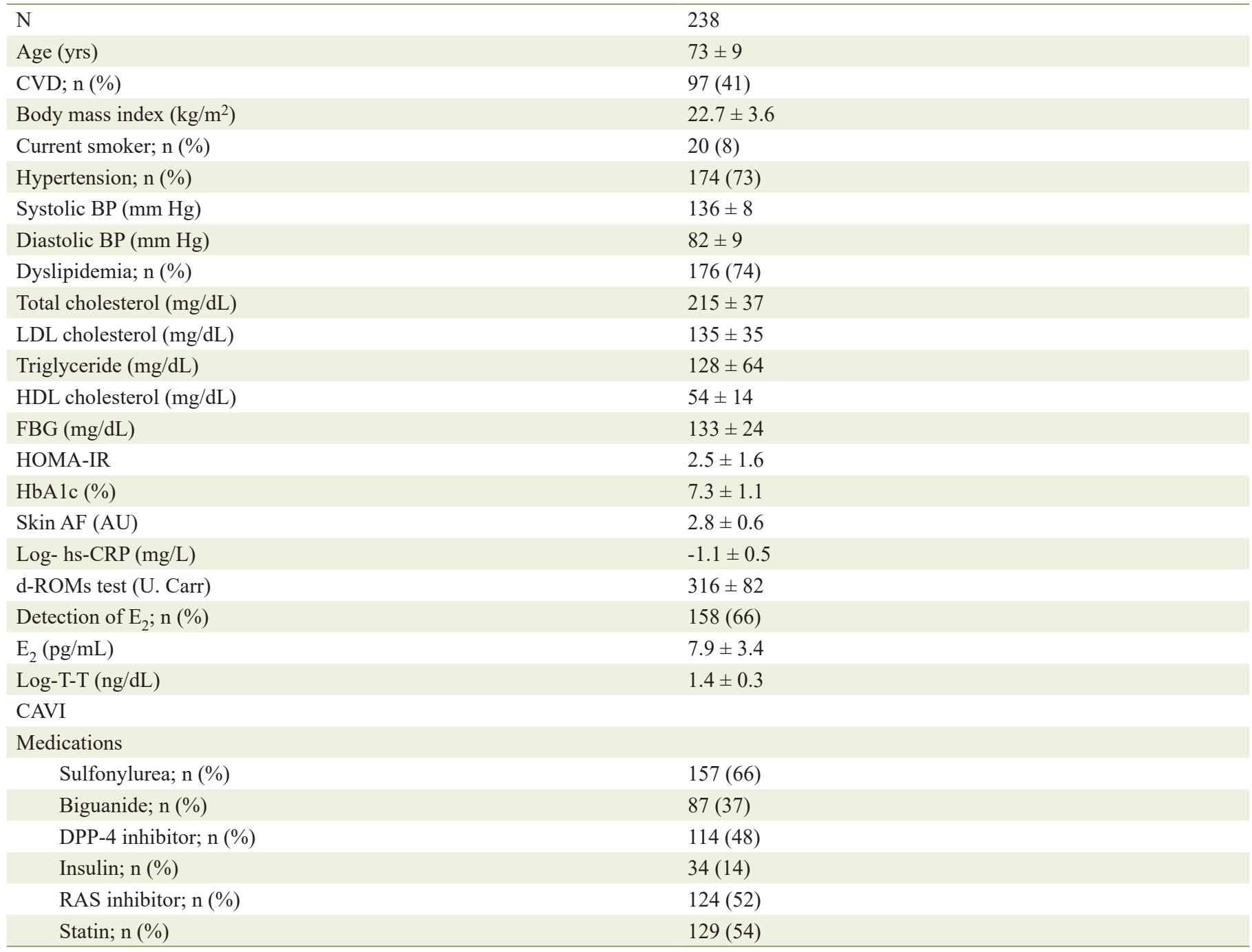

Data are expressed mean \pm SD. CVD: cardiovascular disease; BP: blood pressure; LDL: low-density lipoprotein; HDL: high-density lipoprotein; FBG: fasting blood glucose; HOMA-IR: homeostatic model assessment of insulin resistance; HbA1c: hemoglobin A1c; AF: autofluorescence; hs-CRP: high sensitivity C-reactive protein, d-ROMs: derivatives of reactive oxygen metabolites; $\mathrm{E}_{2}$ : estradiol; T-T: total testosterone; CAVI: cardio-ankle vascular index; DPP: dipeptidyl peptidase; RAS: renin-angiotensin system.
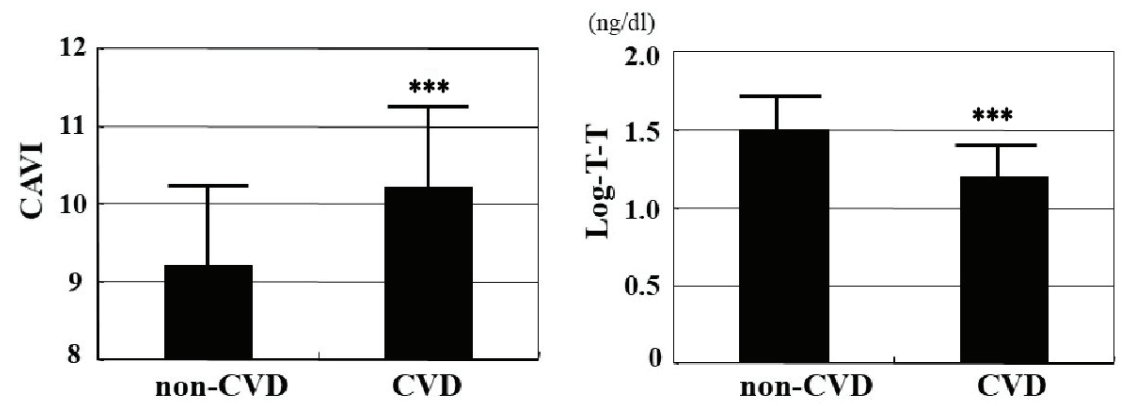

Figure 2. Comparisons of CAVI or T-T between non-CVD and CVD patients. CAVI is significantly higher (CVD vs. non-CVD: 10.2 \pm 1.2 vs. $9.2 \pm 1.0, P<0.001$ ), and log-T-T significantly lower (CVD vs. non-CVD: $1.2 \pm 0.2 \mathrm{ng} / \mathrm{dL}$ vs. $1.5 \pm 0.2 \mathrm{ng} / \mathrm{dL}, \mathrm{P}<0.001$ ) in patients with CVD than those without CVD. CAVI: cardio-ankle vascular index; T-T: total testosterone; CVD: cardiovascular disease. ${ }^{* * *} P<0.001$ vs. non-CVD. 


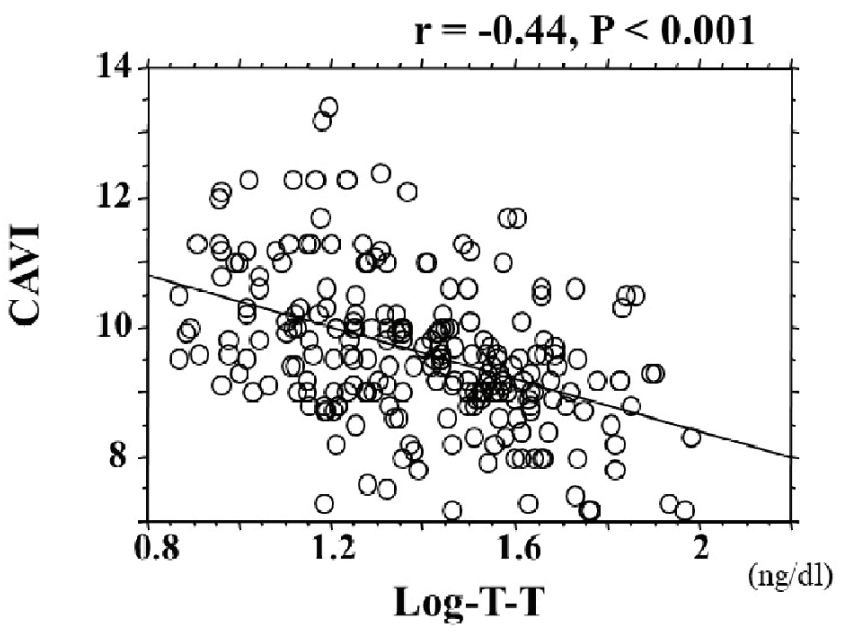

Figure 3. The association between CAVI and T-T. CAVI was significantly negatively correlated with log-T-T $(r=-0.41 ; P<0.001)$. CAVI: cardio-ankle vascular index; T-T: total testosterone.

Table 2. Relationships Between CAVI, T-T and Various Clinical Parameters

\begin{tabular}{|c|c|c|}
\hline & CAVI & Log-T-T \\
\hline & $\mathbf{r}$ & $\mathbf{r}$ \\
\hline Age & $0.38 * * *$ & -0.09 \\
\hline $\operatorname{CVD}(\mathrm{Yes}=1, \mathrm{No}=0)$ & $0.40 * * *$ & $-0.43 * * *$ \\
\hline Body mass index & 0.03 & -0.07 \\
\hline Current smoker $($ Yes $=1$, No $=0)$ & 0.05 & -0.02 \\
\hline Hypertension $(\mathrm{Yes}=1, \mathrm{No}=0)$ & $0.15^{*}$ & $-0.14 *$ \\
\hline Diastolic BP & 0.09 & -0.08 \\
\hline Dyslipidemia $($ Yes $=1$, No $=0)$ & 0.06 & -0.03 \\
\hline Total cholesterol & 0.03 & 0.07 \\
\hline LDL cholesterol & 0.02 & 0.05 \\
\hline Triglyceride & 0.08 & 0.11 \\
\hline $\mathrm{HbAlc}$ & $0.14 *$ & $-0.21 * * *$ \\
\hline Skin AF & $0.32 * * *$ & $-0.22 * * *$ \\
\hline Log- hs-CRP & $0.32 * * *$ & $-0.25 * * *$ \\
\hline d-ROMs test & $0.33 * * *$ & $-0.43 * * *$ \\
\hline Detection of $\mathrm{E}_{2}(\mathrm{Yes}=1, \mathrm{No}=0)$ & $-0.20 * *$ & $0.47 * * *$ \\
\hline $\mathrm{E}_{2}$ & $-0.13 *$ & $0.19 * *$ \\
\hline Sulfonylurea $(\mathrm{Yes}=1, \mathrm{No}=0)$ & 0.09 & 0.08 \\
\hline Biguanide $($ Yes $=1, \mathrm{No}=0)$ & 0.03 & 0.07 \\
\hline DPP-4 inhibitor $(\mathrm{Yes}=1, \mathrm{No}=0)$ & -0.06 & 0.05 \\
\hline Insulin $(\mathrm{Yes}=1, \mathrm{No}=0)$ & 0.1 & 0.06 \\
\hline
\end{tabular}

CAVI: cardio-ankle vascular index; T-T: total testosterone; CVD: cardiovascular disease; BP: blood pressure; LDL: low-density lipoprotein; HDL: high-density lipoprotein; FBG: fasting blood glucose; HOMA-IR: homeostatic model assessment of insulin resistance; HbA1c: hemoglobin A1c; AF: autofluorescence; hs-CRP: high sensitivity C-reactive protein; d-ROMs: derivatives of reactive oxygen metabolites; $\mathrm{E}_{2}$ : estradiol; DPP: dipeptidyl peptidase; RAS: renin-angiotensin system. ${ }^{*} \mathrm{P}<0.05,{ }^{* *} \mathrm{P}<0.01,{ }^{* * *} \mathrm{P}<0.001$. 
Table 3. Multiple Regression Analysis

\begin{tabular}{|c|c|c|}
\hline Explanatory factor & $\beta$ & P value \\
\hline \multicolumn{3}{|l|}{ (A) } \\
\hline Age & 0.31 & $<0.001$ \\
\hline Log-T-T & -0.18 & $<0.01$ \\
\hline Skin AF & 0.14 & $<0.05$ \\
\hline Hypertension & 0.07 & 0.215 \\
\hline \multicolumn{3}{|l|}{ (B) } \\
\hline Detection of $E_{2}$ & 0.26 & $<0.001$ \\
\hline CAVI & -0.19 & $<0.001$ \\
\hline HOMA-IR & -0.11 & 0.057 \\
\hline Hypertension & -0.1 & 0.069 \\
\hline $\mathrm{HbAlc}$ & -0.07 & 0.168 \\
\hline
\end{tabular}

(A): Subordinate factor is CAVI, $R^{2}=0.38 ; P<0.001 ;(B)$ : Subordinate factor is log-T-T, $R^{2}=0.43 ; P<0.001$. CVD: cardiovascular disease; T-T: total testosterone; AF: autofluorescence; d-ROMs: derivatives of reactive oxygen metabolites; $\mathrm{E}_{2}$ : estradiol; CAVI: cardio-ankle vascular index; HOMA-IR: homeostatic model assessment of insulin resistance; HbA1c: hemoglobin A1c.

health problems, including arterial dysfunction. Furthermore, testosterone is known as the main source of estrogen production. Moreover, this study indicated that detection of estradiol was selected as one of the strongest variables for log-T-T as a subordinate factor. In addition, the univariate analysis showed that serum estradiol concentration is significantly negatively correlated with CAVI. However, multivariate analysis indicated that serum estradiol concentration was not selected as an independent variable for CAVI as a subordinate factor. Kernohan et al reported that administration of estradiol on female patients with type 2 DM does not improve PWV [28]. Honisett et al also reported that hormone therapy using estrogen and progesterone impairs endothelial function in postmenopausal female patients with type 2 DM treated with rosiglitazone [29]. Therefore, this result and previous studies suggested that testosterone can significantly improve the arterial function better than estrogen in female patients with type 2 DM. Further studies were need that testosterone administration improves arterial dysfunction, such as CAVI in female patients with type 2 DM with low testosterone concentration.

Several researchers reported that AGEs play an important role in the pathogenesis of diabetic complication. Basic studies have reported that AGEs or their receptors can induce inflammation, oxidative stress, and calcification in the vascular cells, such as endothelial or smooth muscle cells [30-32]. In addition, clinical studies have also indicated skin AF is significantly associated with physiological markers of arterial function including CAVI $[15,33,34]$. The results of this study also indicated the importance of AGEs on arterial dysfunction in female patients with type 2 DM. However, skin AF was in- dependently inversely associated with $\log -\mathrm{T}-\mathrm{T}$ in this study. Some reports demonstrated the association between AGEs and testosterone $[35,36]$. Zhao et al reported that AGEs inhibit testosterone secretion using animal models [35]. However, Xie et al reported that physiological testosterone prevented AGE-induced injury in human endothelial cells [36]. Thus, this result and previous studies indicated that low testosterone concentration is significantly associated with high AGEs, which consequently promotes arterial dysfunction.

Increased oxidative stress is well known to be a crucial role in the progression of atherosclerosis. In addition, several clinical studies have reported that oxidative stress levels in vivo are significantly positively associated with arterial function markers [15, 37-39]. This study also indicated that d-ROMs test, an oxidative stress marker in vivo, was selected as an independent factor for CAVI, suggesting that increased oxidative stress was closely associated with progression of arterial dysfunction in female patients with type 2 DM. However, the association between oxidative stress and testosterone in female patients remains controversial. Some studies have indicated that blood testosterone concentration was inversely associated with oxidative stress levels $[40,41]$. Other studies reported that high testosterone concentrations were significantly associated with increased oxidative stress levels [42, 43]. However, RoviraLlopis et al reported that low testosterone levels are related to increased reactive oxygen species production in male patients with type 2 DM [44]. This study also indicated that testosterone was inversely associated with oxidative stress levels in female patients with type 2 DM. However, detailed mechanisms regarding the relationship between testosterone and oxidative 
stress in type 2 DM was not fully understood. Additional basic and clinical studies were desirable to clarify the relationship between these 2 markers in type $2 \mathrm{DM}$.

\section{Limitations}

This study has several limitations. First, the medical treatments for type $2 \mathrm{DM}$, hypertension, and/or dyslipidemia may have influenced the study results. Second, angiography, computed tomography, magnetic resonance imaging, and echocardiography were not fully performed on all patients without CVD. Therefore, asymptomatic CVD may have been undetected. Third, the HOMA-IR has limitations as an insulin resistance marker, especially in patients with high blood glucose levels. This study included a substantial number of patients with high fasting blood glucose levels. Therefore, additional studies using other accurate insulin resistance markers, such as a glucose clamp test, are warranted to evaluate the relationship between insulin resistance and T-T or CAVI. Finally, this was crosssectional study conducted in a single unit with a relatively small sample size. Additional prospective studies, including interventional therapy evaluation, are required to clarify the clinical significance of T-T as a risk factor of arterial dysfunction or CVD incidence in female patients with type 2 DM.

\section{Conclusions}

In conclusion, this study showed that T-T is independently inversely associated with CAVI, indicating that low testosterone level is a considerable risk factor for the progression of arterial dysfunction in female patients with type 2 DM.

\section{Conflict of Interest}

The author has reported no conflict of interest.

\section{Grant Support}

None.

\section{References}

1. Doi Y, Ninomiya T, Hata J, Fukuhara M, Yonemoto K, Iwase $\mathrm{M}$, Iida $\mathrm{M}$, et al. Impact of glucose tolerance status on development of ischemic stroke and coronary heart disease in a general Japanese population: the Hisayama study. Stroke. 2010;41(2):203-209.

2. Madsen TE, Khoury JC, Alwell KA, Moomaw CJ, Demel SL, Flaherty ML, Woo D, et al. Sex differences in cardiovascular risk profiles of ischemic stroke patients with diabetes in the Greater Cincinnati/Northern Kentucky Stroke Study. J Diabetes. 2018;10(6):496-501.

3. Yusuf S, Hawken S, Ounpuu S, Dans T, Avezum A, La- nas F, McQueen M, et al. Effect of potentially modifiable risk factors associated with myocardial infarction in 52 countries (the INTERHEART study): case-control study. Lancet. 2004;364(9438):937-952.

4. Bundhun PK, Pursun M, Huang F. Are women with type 2 diabetes mellitus more susceptible to cardiovascular complications following coronary angioplasty?: a metaanalysis. BMC Cardiovasc Disord. 2017;17(1):207.

5. Johansson I, Dahlstrom U, Edner M, Nasman P, Ryden L, Norhammar A. Risk factors, treatment and prognosis in men and women with heart failure with and without diabetes. Heart. 2015;101(14):1139-1148.

6. Laughlin GA, Barrett-Connor E, Bergstrom J. Low serum testosterone and mortality in older men. J Clin Endocrinol Metab. 2008;93(1):68-75.

7. Akishita M, Hashimoto M, Ohike Y, Ogawa S, Iijima K, Eto M, Ouchi Y. Low testosterone level as a predictor of cardiovascular events in Japanese men with coronary risk factors. Atherosclerosis. 2010;210(1):232-236.

8. Madhu SV, Aslam M, Aiman AJ, Siddiqui A, Dwivedi S. Prevalence of hypogonadism in male Type 2 diabetes mellitus patients with and without coronary artery disease. Indian J Endocrinol Metab. 2017;21(1):31-37.

9. Morgunov LY, Denisova IA, Rozhkova TI, Stakhovskaya LV, Skvortsova VI. Hypogonadism and its treatment following ischaemic stroke in men with type 2 diabetes mellitus. Aging Male. 2018:1-10.

10. Shaw LJ, Bairey Merz CN, Azziz R, Stanczyk FZ, Sopko G, Braunstein GD, Kelsey SF, et al. Postmenopausal women with a history of irregular menses and elevated androgen measurements at high risk for worsening cardiovascular event-free survival: results from the National Institutes of Health - National Heart, Lung, and Blood Institute sponsored Women's Ischemia Syndrome Evaluation. J Clin Endocrinol Metab. 2008;93(4):1276-1284.

11. Patel SM, Ratcliffe SJ, Reilly MP, Weinstein R, Bhasin S, Blackman MR, Cauley JA, et al. Higher serum testosterone concentration in older women is associated with insulin resistance, metabolic syndrome, and cardiovascular disease. J Clin Endocrinol Metab. 2009;94(12):47764784.

12. Sievers C, Klotsche J, Pieper L, Schneider HJ, Marz W, Wittchen HU, Stalla GK, et al. Low testosterone levels predict all-cause mortality and cardiovascular events in women: a prospective cohort study in German primary care patients. Eur J Endocrinol. 2010;163(4):699-708.

13. Shirai K, Hiruta N, Song M, Kurosu T, Suzuki J, Tomaru T, Miyashita Y, et al. Cardio-ankle vascular index (CAVI) as a novel indicator of arterial stiffness: theory, evidence and perspectives. J Atheroscler Thromb. 2011;18(11):924938.

14. Chung SL, Yang CC, Chen CC, Hsu YC, Lei MH. Coronary artery calcium score compared with cardio-ankle vascular index in the prediction of cardiovascular events in asymptomatic patients with type 2 diabetes. J Atheroscler Thromb. 2015;22(12):1255-1265.

15. Hitsumoto T. Clinical significance of cardio-ankle vascular index as a cardiovascular risk factor in elderly patients with type 2 diabetes mellitus. J Clin Med Res. 
2018;10(4):330-336.

16. Meerwaldt R, Links TP, Graaff R, Hoogenberg K, Lefrandt JD, Baynes JW, Gans RO, et al. Increased accumulation of skin advanced glycation end-products precedes and correlates with clinical manifestation of diabetic neuropathy. Diabetologia. 2005;48(8):1637-1644.

17. Friedewald WT, Levy RI, Fredrickson DS. Estimation of the concentration of low-density lipoprotein cholesterol in plasma, without use of the preparative ultracentrifuge. Clin Chem. 1972;18(6):499-502.

18. Matthews DR, Hosker JP, Rudenski AS, Naylor BA, Treacher DF, Turner RC. Homeostasis model assessment: insulin resistance and beta-cell function from fasting plasma glucose and insulin concentrations in man. Diabetologia. 1985;28(7):412-419.

19. Cesarone MR, Belcaro G, Carratelli M, Cornelli U, De Sanctis MT, Incandela L, Barsotti A, et al. A simple test to monitor oxidative stress. Int Angiol. 1999;18(2):127-130.

20. Endo K, Saiki A, Ohira M, Miyashita Y, Shirai K. Cardioankle vascular index may reflect endothelial function in type 2 diabetes. Int J Clin Pract. 2011;65(11):1200-1201.

21. Kim KJ, Lee BW, Kim HM, Shin JY, Kang ES, Cha BS, Lee EJ, et al. Associations between cardio-ankle vascular index and microvascular complications in type 2 diabetes mellitus patients. J Atheroscler Thromb. 2011;18(4):328336.

22. Chen YQ, Zhao J, Jin CW, Li YH, Tang MX, Wang ZH, Zhang W, et al. Testosterone delays vascular smooth muscle cell senescence and inhibits collagen synthesis via the Gas6/Axl signaling pathway. Age (Dordr). 2016;38(3):60.

23. Deenadayalu VP, White RE, Stallone JN, Gao X, Garcia AJ. Testosterone relaxes coronary arteries by opening the large-conductance, calcium-activated potassium channel. Am J Physiol Heart Circ Physiol. 2001;281(4):H17201727.

24. Hak AE, Witteman JC, de Jong FH, Geerlings MI, Hofman A, Pols HA. Low levels of endogenous androgens increase the risk of atherosclerosis in elderly men: the Rotterdam study. J Clin Endocrinol Metab. 2002;87(8):3632-3639.

25. Vlachopoulos C, Ioakeimidis N, Miner M, Aggelis A, Pietri P, Terentes-Printzios D, Tsekoura D, et al. Testosterone deficiency: a determinant of aortic stiffness in men. Atherosclerosis. 2014;233(1):278-283.

26. Akishita M, Hashimoto M, Ohike Y, Ogawa S, Iijima K, Eto M, Ouchi Y. Low testosterone level is an independent determinant of endothelial dysfunction in men. Hypertens Res. 2007;30(11):1029-1034.

27. Corrigan FE, 3rd, Al Mheid I, Eapen DJ, Hayek SS, Sher S, Martin GS, Quyyumi AA. Low testosterone in men predicts impaired arterial elasticity and microvascular function. Int J Cardiol. 2015;194:94-99.

28. Kernohan AF, Spiers A, Sattar N, Hillier C, Cleland SJ, Small M, Lumsden MA, et al. Effects of low-dose continuous combined HRT on vascular function in women with type 2 diabetes. Diab Vasc Dis Res. 2004;1(2):82-88.

29. Honisett SY, Stojanovska L, Sudhir K, Kingwell BA, Dawood T, Komesaroff PA. Hormone therapy impairs endothelial function in postmenopausal women with type 2 diabetes mellitus treated with rosiglitazone. J Clin Endo- crinol Metab. 2004;89(9):4615-4619.

30. Yan SF, Ramasamy R, Schmidt AM. The RAGE axis: a fundamental mechanism signaling danger to the vulnerable vasculature. Circ Res. 2010;106(5):842-853.

31. Chang JS, Wendt T, Qu W, Kong L, Zou YS, Schmidt $\mathrm{AM}$, Yan SF. Oxygen deprivation triggers upregulation of early growth response- 1 by the receptor for advanced glycation end products. Circ Res. 2008;102(8):905-913.

32. Suga T, Iso T, Shimizu T, Tanaka T, Yamagishi S, Takeuchi $\mathrm{M}$, Imaizumi T, et al. Activation of receptor for advanced glycation end products induces osteogenic differentiation of vascular smooth muscle cells. J Atheroscler Thromb. 2011;18(8):670-683.

33. Ninomiya H, Katakami N, Sato I, Osawa S, Yamamoto Y, Takahara M, Kawamori D, et al. Association between subclinical atherosclerosis markers and the level of accumulated advanced glycation end-products in the skin of patients with diabetes. J Atheroscler Thromb. 2018;25(12):1274-1284.

34. Ueno H, Koyama H, Tanaka S, Fukumoto S, Shinohara K, Shoji T, Emoto M, et al. Skin autofluorescence, a marker for advanced glycation end product accumulation, is associated with arterial stiffness in patients with end-stage renal disease. Metabolism. 2008;57(10):1452-1457.

35. Zhao YT, Qi YW, Hu CY, Chen SH, Liu Y. Advanced glycation end products inhibit testosterone secretion by rat Leydig cells by inducing oxidative stress and endoplasmic reticulum stress. Int J Mol Med. 2016;38(2):659-665.

36. Xie Y, Yu D, Wu J, Li L. Protective effects of physiological testosterone on advanced glycation end productinduced injury in human endothelial cells. Mol Med Rep. 2017;15(3):1165-1171.

37. Hitsumoto T. Clinical significance of the augmentation index in patients with preserved kidney function. J Nippon Med Sch. 2012;79(6):422-429.

38. Gomez-Marcos MA, Blazquez-Medela AM, GamellaPozuelo L, Recio-Rodriguez JI, Garcia-Ortiz L, MartinezSalgado C. Serum superoxide dismutase is associated with vascular structure and function in hypertensive and diabetic patients. Oxid Med Cell Longev. 2016;2016:9124676.

39. Liu Q, Han L, Du Q, Zhang M, Zhou S, Shen X. The association between oxidative stress, activator protein-1, inflammatory, total antioxidant status and artery stiffness and the efficacy of olmesartan in elderly patients with mild-to-moderate essential hypertension. Clin Exp Hypertens. 2016;38(4):365-369.

40. Noguera JC, Alonso-Alvarez C, Kim SY, Morales J, Velando A. Yolk testosterone reduces oxidative damages during postnatal development. Biol Lett. 2011;7(1):9395.

41. Hitsumoto T. Relationship between serum total testosterone concentration and augmentation index at radial artery in Japanese postmenopausal patients. J Clin Med Res. 2017;9(10):872-878.

42. Beyazit F, Yilmaz N, Balci O, Adam M, Yaman ST. Evaluation of oxidative stress in women with polycystic ovarian syndrome as represented by serum ischemia modified albumin and its correlation with testosterone and insulin resistance. Intern Med. 2016;55(17):2359-2364. 
43. Costa TJ, Ceravolo GS, dos Santos RA, de Oliveira MA, Araujo PX, Giaquinto LR, Tostes RC, et al. Association of testosterone with estrogen abolishes the beneficial effects of estrogen treatment by increasing ROS generation in aorta endothelial cells. Am J Physiol Heart Circ Physiol. 2015;308(7):H723-732.
44. Rovira-Llopis S, Banuls C, de Maranon AM, Diaz-Morales N, Jover A, Garzon S, Rocha M, et al. Low testosterone levels are related to oxidative stress, mitochondrial dysfunction and altered subclinical atherosclerotic markers in type 2 diabetic male patients. Free Radic Biol Med. 2017;108:155-162. 